\title{
Effect of coolant temperature and mass flow on film cooling of turbine blades
}

\author{
VIJAY K. GARG \\ AYT Corporation, co NASA Lewis Research Center, Mail Stop 5-11. Cleveland. OH 44135, U.S.A. \\ and \\ RAYMOND E. GAUGLER \\ Turbomachinery Flow Physics Branch, Internal Fluid Mechanics Division, NASA Lewis Research \\ Center. Mail Stop 5-11, Cleveland. OH 44135. U.S.A.
}

(Received 20 Octoher 1995 and in final form 30 January 1996)

\begin{abstract}
A three-dimensional Navier - Stokes code has been used to study the effect of coolant temperature, and coolant to mainstream mass flow ratio on the adiabatic effectiveness of a film-cooled turbine blade. The blade chosen is the VKI rotor with six rows of cooling holes including three rows on the shower head. The mainstream is akin to that under real engine conditions with stagnation temperature $=1900 \mathrm{~K}$ and stagnation pressure $=3 \mathrm{MPa}$. Generally, the adiabatic effectiveness is lower for a higher coolant temperature due to nonlinear effects via the compressibility of air. However, over the suction side of shower-head holes, the effectiveness is higher for a higher coolant temperature than that for a lower coolant temperature when the coolant to mainstream mass flow ratio is $5 \%$ or more. For a fixed coolant temperature, the effectiveness passes through a minima on the suction side of shower-head holes as the coolant to mainstream mass flow ratio increases, while on the pressure side of shower-head holes, the effectiveness decreases with increase in coolant mass flow due to coolant jet lift-off. In all cases, the adiabatic effectiveness is highly three-dimensional. Copyright 1996 Elsevier Science Ltd.
\end{abstract}

\section{INTRODUCTION}

The search for a better performance of gas turbine engines has led to higher turbine inlet temperatures. Modern gas turbine engines are designed to operate at inlet temperatures of $1800-2000 \mathrm{~K}$, which are far beyond the allowable metal temperatures. Under these conditions, the turbine blades need to be cooled in order to ensure a reasonable lifetime. This calls for an efficient cooling system. Discrete jet film cooling is one of the techniques used to protect the blades and endwalls that are thermally exposed. Since the injected cooler air is bled directly from the compressor before it passes through the combustion chamber, the best compromise between admissible metal temperature and aerodynamic efficiency becomes a major objective in cooled turbine blade design.

A considerable effort has been devoted to understanding the coolant film behavior and its interaction with the mainstream flow. The film cooling performance is influenced by the wall curvature, threedimensional external flow structure, free-stream turbulence, compressibility, flow unsteadiness, the hole size, shape and location, and the angle of injection. Many studies on film cooling have been confined to simple geometries, for example. two-dimensional flat and curved plates in steady, incompressible flow. An excellent survey of the work up to 1971 has been provided by Goldstein [1]. Several further studies in this field have been summarized by Garg and Gaugler $[2-4]$. This summary indicates that there is still a considerable experimental effort devoted to flat plate studies with somewhat unrealistic parameters, such as the length to diameter ratio, the density ratio, etc. Besides, wall curvature and compressibility effects cannot be studied in such a situation. On the other hand, the computational effort is almost solely devoted to the real blade, though still stationary except for the analysis of Weigand and Harasgama [5]. Also, while the analysis of Liu et al. [6] forms one extreme in that no resolution of the mixing of coolant with the main flow was attempted, the analysis of Weigand and Harasgama [5] and of Leylek and Zerkle [7] represents the other extreme, with the hole pipe and plenum chamber also discretized. Both these extremes have merits and limitations.

While the poor resolution of Liu e' al. [6] perhaps prevented them from presenting any heat transfer results, they could consider the whole vane along with the hub and shroud endwalls containing 34 rows with hundreds of film cooling holes. On the other hand, Leylek and Zerkle analyzed just one row of holes on a flat plate (just one hole for computational purposes), while Weigand and Harasgama [5] considered a total of nine holes in two rows on a rotating blade, but with (unrealistic) injection in the tangential direction. 


\section{NOMENCLATURE}

\begin{tabular}{|c|c|}
\hline$B_{\mathrm{p}}$ & blowing parameter \\
\hline & {$\left[=\left(\rho_{\mathrm{c}} V_{\mathrm{c}}\right)\left[\rho_{\mathrm{s}}\left(R T_{\mathrm{c}}\right)^{12}\right\}\right]$} \\
\hline$c^{\prime}$ & true chord of the blade \\
\hline$d$ & coolant hole diameter \\
\hline$h$ & $\begin{array}{l}\text { heat transfer coefficient based on } \\
\left(T_{v}-T_{w}\right)\end{array}$ \\
\hline$I$ & momentum flow \\
\hline$m$ & mass flow rate \\
\hline$p$ & pressure \\
\hline$s$ & $\begin{array}{l}\text { distance from the leading edge along } \\
\text { the pressure or suction surface }\end{array}$ \\
\hline$S$ & $\begin{array}{l}=s / s_{\mathrm{m}} \text { on suction surface, } \\
\text { and }=-s / s_{\mathrm{m}} \text { on pressure surface }\end{array}$ \\
\hline$T$ & temperature \\
\hline$V_{c}$ & $\begin{array}{l}\text { average coolant velocity at the hole } \\
\text { exit }\end{array}$ \\
\hline$y$ & $\begin{array}{l}y \text {-coordinate of the Cartesian } \\
\text { coordinate system with origin at the } \\
\text { geometric stagnation point }\end{array}$ \\
\hline
\end{tabular}
$y^{+} \quad$ dimensionless distance of the first point off the blade surface
$z \quad z$-coordinate along the span.

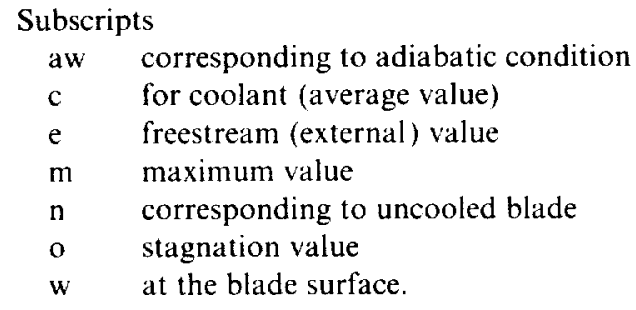

While Leylek and Zerkle's approach is good to resolve the near-hole and within-hole physics, it cannot be extended to a real blade with hundreds of holes, at least with present-day computers. It can be used to feed the hole-exit information into a middle-of-theroad' approach taken by Garg and Gaugler [3], wherein appropriate boundary conditions are imposed at the hole exits on the blade surface, instead of resolving the coolant flow within the hole pipe. Garg and Gaugler's analysis provides proper resolution for accurate prediction of surface heat transfer coefficients, and is still computationally manageable for analyzing the whole blade with hundreds of holes. For example, Garg and Gaugler's computational span was about $20 \%$ of the total span for the $\mathrm{C} 3 \mathrm{X}$ vane with nine rows of holes. They used about one million grid points with 30 holes in the computational domain.

Herein, we follow the analysis of Garg and Gaugler [3] in order to study the effect of coolant temperature, and coolant to mainstream mass flow ratio on the adiabatic effectiveness of the film-cooled VKI rotor with six rows of film cooling holes, including three rows on the shower-head. We may also point out that the suction and pressure surface holes on the VKI rotor are conical, while the shower-head holes are cylindrical.

\section{ANALYSIS}

The three-dimensional Navier-Stokes code of Arnone et al. [8] for the analysis of turbomachinery flows was modified by Garg and Gaugler [3] to include film cooling effects. Briefly, the code is an explicit, multigrid, cell-centered, finite volume code with an algebraic turbulence model. The Navier-Stokes equations in a rotating Cartesian coordinate system are mapped onto a general body-fitted coordinate system using standard techniques. The multistage RungeKutta scheme developed by Jameson et al. [9] is used to advance the flow solution in time from an initial guess to the steady state. A spatially varying time step along with a CFL number of 5 was used to speed convergence to the steady state. Eigenvalue-scaled artificial dissipation and variable-coefficient implicit residual smoothing are used along with a fullmultigrid method.

The effects of film cooling have been incorporated into the code in the form of appropriate boundary conditions at the hole locations on the blade surface. Each hole exit is represented by several control volumes (about 20) having a total area equal to the area of the hole exit, and passing the same coolant mass flow. Different velocity and temperature profiles for the injected gas can be specified at the hole exit. For the cases reported here, turbulent profiles $(1 / 7$ th power-law) for the coolant velocity and temperature distribution at the hole exit were specified, in conformity with the observation of Leylek and Zerkle [7], since the hole-length to diameter ratio for the VKI rotor is greater than 3.0. Leylek and Zerkle [7] found that for high hole-length to diameter ratios $(\geqslant 3.0)$ and high blowing ratios $(\geqslant 1.0)$, the velocity profile at the hole exit is akin to the $1 / 7$ th power-law profile.

The blade surface was considered adiabatic in order to compute the adiabatic effectiveness. The algebraic mixing length turbulence model of Baldwin and Lomax [10] was used. This model was designed for the prediction of wall bounded turbulent shear layers, and may not be appropriate for flows with massive 
separations or large vortical structures. Thus, this model is likely to be invalid in a number of turbomachinery applications, but for turbine blades, the boundary layers generally experience a favorable pressure gradient whereby this model is more likely to be valid. It hals been used satisfactorily by Boyle and Giel [11]. Ameri and Arnone [12, 13], and Boyle and Ameri [14] for heat transfer calculations on turbine blades without film cooling, and by Hall et al. [15], and Garg and Gaugler [3] with film cooling. In fact, Ameri and Arnone [13] compared the Baldwin Lomax model and Coakley"s $q-(1)$ model against the experimental data of Graziani et al. [16], and found that the algebraic model was able to produce many of the flow features better than the two-equation model. They further state that this conclusion is strengthened when one takes into account the relative economy of computations with the algebraic model. It is known [17] that two-equation models are also not satisfactory in the presence of film cooling. Perhaps the multipletime-scale turbulence model of Kim and Benson [18] may be more appropriate. However, use of this model is computationally very expensive since it involves solving four more partial differential equations in addition to the five at present, all coupled.

\section{VKI ROTOR}

Figure 1 shows the VKI rotor geometry along with cooling hole details. Three staggered rows of cylindrical cooling holes $(d=0.8 \mathrm{~mm} ; s d=0, \pm 2.85)$ were located around the leading edge. The row and hole spacings were, respectively, 2.28 and $2.48 \mathrm{~mm}$. These holes were spanwise angled at 30 from the tangential direction and drilled in a plane perpendicular to the blade surface. Two staggered rows of conical holes $(d=0.8 \mathrm{~mm} ; s d=20.6 .23 .7)$ were located on the suction side. The row and hole spacings were, respectively, 2.48 and $2.64 \mathrm{~mm}$. These holes were inclined at 37 and 43 with respect to the local blade surface and drilled in a plane perpendicular to the span. One row of conical holes $(d=0.8 \mathrm{~mm}$; $s d=-31.5)$ was located along the pressure side. The hole spacing was $2.64 \mathrm{~mm}$. These holes were inclined at 35 with respect to the local blade surface and drilled in a plane perpendicular to the span. The conical holes had a half cone angle of 10 and an exit diameter of $0.95 \mathrm{~mm}$ at the blade surface. as shown in Fig. 1. More details are available in Camci and Arts [19], along with the experimental data.

\section{COMPUTATIONAL DETAILS}

The hole spacing in the span direction was assumed to be $2.56 \mathrm{~mm}(=3.2 d)$ for all holes on the VKI rotor. representing a deviation of $\pm 3 \%$ from the actual values of 2.48 and $2.64 \mathrm{~mm}$. The computational span, shown in Fig. 2, is only a part of the real span. The ordinate in Fig. 2 denotes the distance along the blade surface in the spanwise direction, while the abscissa denotes the distance along the blade surface in the streamwise direction, both normalized by the hole diameter, d. It may be noted that the abscissa in Fig. 2 has breaks so as to accommodate all the rows of holes. The shape and orientation of the hole openings in Fig. 2 is a direct consequence of the angles the holes make with the spanwise or streamwise direction. The pattern of holes shown in Fig. 2 is repeated in the spanwise direction. Periodic boundary conditions are imposed due to shower-head injection on the ends of the computational span.

Since the cylindrical hole diameter is $0.8 \mathrm{~mm}$, the grid size has to be varied along the blade chord. For computational accuracy, the ratio of two adjacent grid sizes in any direction was kept within $0.76-1.3$. A periodic C-grid with about 320000 grid points was used. The grid used was $353 \times 53 \times 17$, where the first number represents the number of grid points along the main flow direction, the second in the blade-toblade direction. and the third in the span direction. Normal to the blade surface is the dense viscous grid. with $y^{+}<1$ for the first point off the blade surface, following Boyle and Giel [11]. Computations were run on the 8-processor Cray YMP supercomputer at the NASA Lewis Research Center, and on the 16-processor C-90 supercomputer at NASA Ames Research Center. The code requires about 20 million words (Mw) of storage and takes about $6.5 \mathrm{~s}$ per iteration (full-multigrid) on the C-90 machine. For a given grid, the first adiabatic blade case requires about 2500 iterations to converge, while subsequent cases (corresponding to different values of the parameters) for the same grid require about 900 iterations starting with the solution for the previous case.

\section{RESULTS AND DISCUSSION}

Before discussing the present results, we provide a comparison (taken from ref. [20]) for the normalized heat transfer coefficient at the blade surface with the experimental data of Camci and Arts [19]. denoted by $\square$, at mid-span. For this comparison shown in Fig. 3, the blade was specified to be isothermal with $T_{\mathrm{w}} T_{\mathrm{b}}=0.7$. In this figure, $h_{\mathrm{n}}$ corresponds to the heat transfer coefficient at an uncooled blade surface. Also, the abscissa represents the surface distance along the blade normalized by the true chord. The six short vertical lines in the center bottom of this figure denote the location of film cooling rows. The comparison is fair. While more comparison for the heat transfer coefficient is available in ref. [20], no comparison can be provided for the adiabatic effectiveness due to lack of experimental data for it.

The present results were obtained for air $(j=1.4)$ with the inlet total pressure. $p_{0}=3 \mathrm{MPa}$, inlet total temperature, $T_{n}=1900 \mathrm{~K}$, exit Mach number $\approx 0.87$. and exit Reynolds number based on the axial chord $\approx 2.7 \times 10^{6}$. The coolant temperature, $T_{c}$, was taken to be $0.5 T_{0}$ or $0.7 T_{0}$ (so that the density ratio is about 2.0 or 1.5 ), while the blowing parameter, $B_{\mathrm{p}}$. 

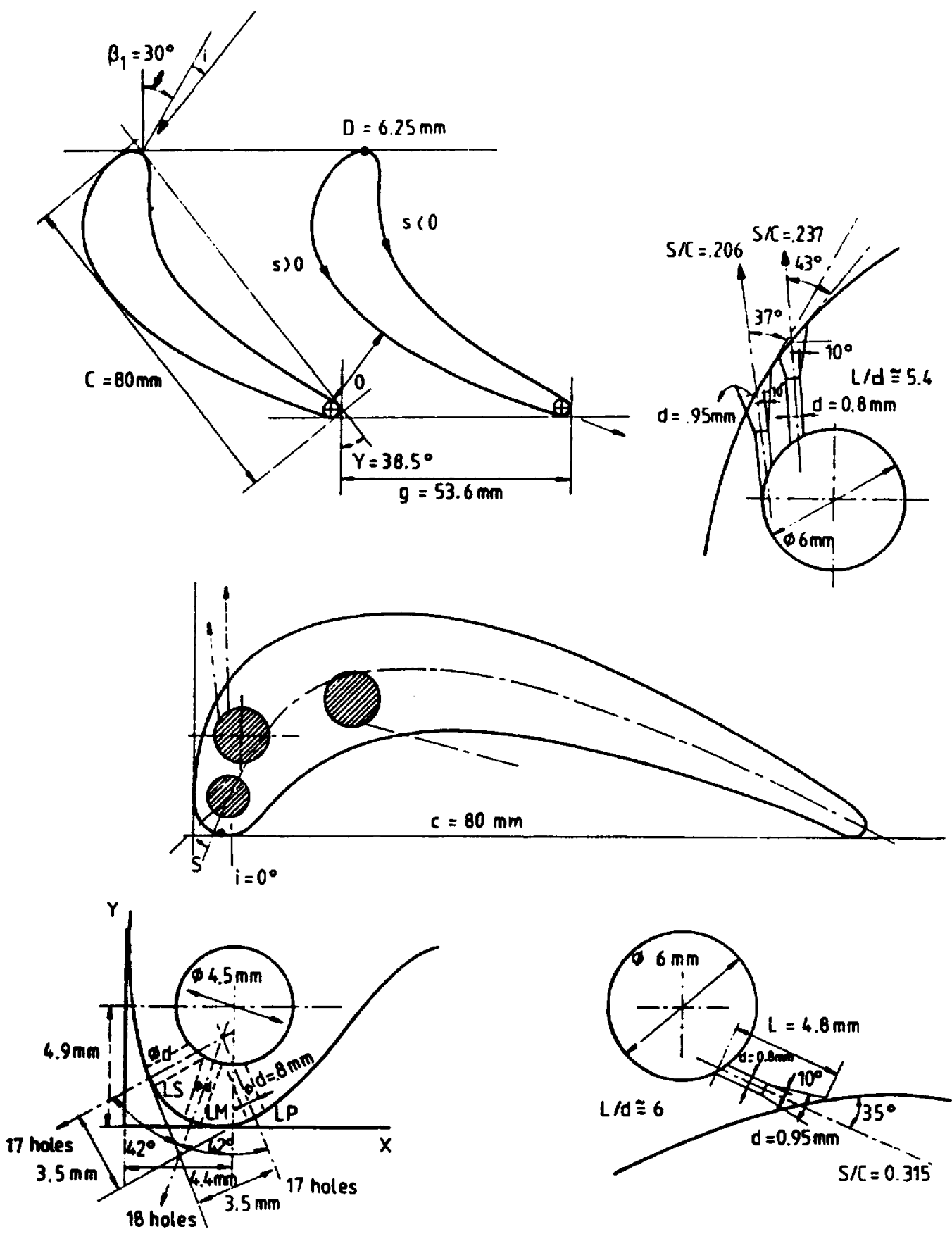

Fig. 1. VKI rotor and cooling hole details.

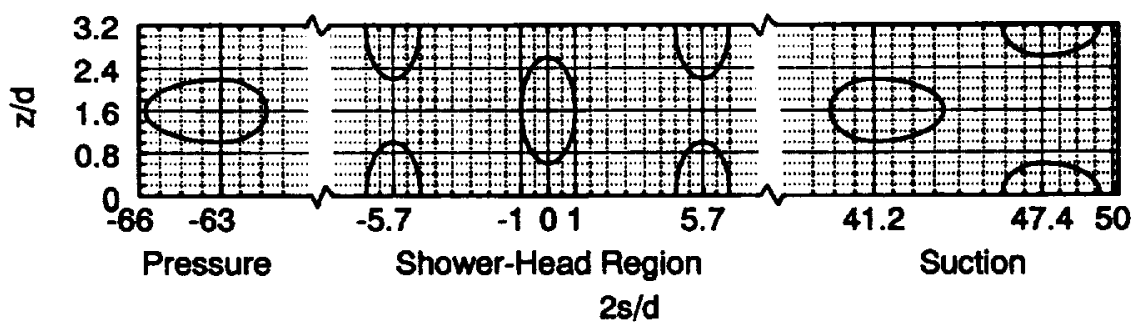

Fig. 2. Computational span for the VKI rotor. 


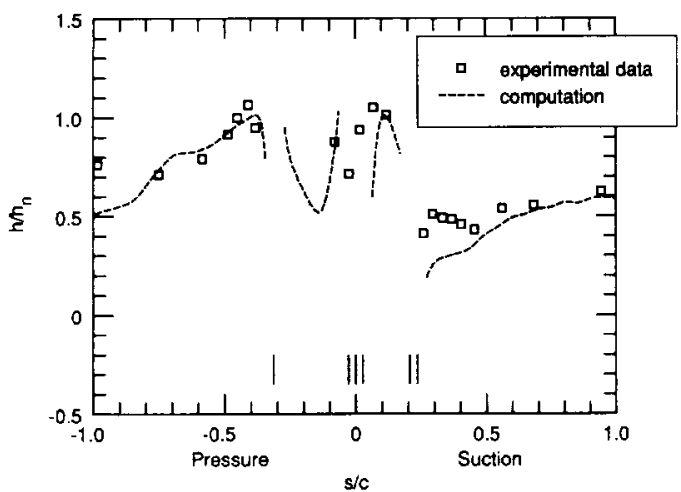

Fig. 3. Comparison with experimental data for the normalized heat transfer coefficient at mid-span $\left(m_{\mathrm{v}} m_{\mathrm{o}}=\right.$ $3.09 \%$ ).

was varied so that the ratio of coolant mass flow to inlet mass flow changed from about 2 to $7 \%$. For each case, $B_{\mathrm{p}}$ was specified the same value for all holes. We may point out that for film cooling on a turbine blade, it is better to use the blowing parameter than the usual blowing ratio, since the latter is based on the local free-stream velocity and density that change all over the airfoil. For injection at the stagnation line, for example, the blowing ratio is infinite, while the blowing parameter is finite. The term 'blowing ratio " perhaps originated with fundamental studies of a jet in crossflow for which the blowing ratio is akin to the blowing parameter.

Figures 4 and 5 show the adiabatic effectiveness contours over the VKI rotor for $T_{\mathrm{c}} T_{\mathrm{o}}=0.5$ and 0.7 . respectively. In each figure, results are provided for four values of the coolant to inlet mass flow ratio. The effectiveness contours are given at intervals of 0.1 , and clearly exhibit strong streamwise as well as spanwise variation. We may point out that while the abscissa represents about $75.9 \mathrm{~mm}$ of streamwise distance on the VKI rotor in Figs. 4 and 5, the ordinate represents only $2.56 \mathrm{~mm}$ of the computational span. For the sake of clarity, the abscissa in these figures covers only $40 \%$ of the blade surface on either side of the stagnation line, with $S=0.4$ on the suction surface corresponding to $s / d \approx 52.7$, while $S=-0.4$ on the pressure surface corresponds to $s d \approx-42.1$. From Fig. 4 , it is clear that downstream of the shower-head holes on the pressure side $(0>S>-0.4)$ the effectiveness is maximum when $m_{c} / m_{\mathrm{o}} \approx 2 \%$. Also, downstream of the shower-head holes on the suction side $(0<S<0.15)$, the effectiveness passes through a minima as $m_{\mathrm{c}} / m_{\mathrm{c}}$ increases from about 2 to $7 \%$. Though not evident from Fig. 4 , it was found that $\eta$ increases downstream of the holes on the pressure and suction sides with increase in the coolant mass flow. Also, over about $10-20 \%$ of chord downstream of the holes on the pressure and suction surfaces, the effectiveness values exhibit a wavelike behavior with higher values directly downstream of the holes and lower values between the holes.

The results in Fig. 5 are very similar to those in Fig.
4. Generally, the effectiveness is lower for $T_{\mathrm{c}} / T_{0}=0.7$ than that for $T_{\mathrm{c}} / T_{0}=0.5$, except over the suction side of shower-head holes $(0<S<0.15)$ where $\eta$ for $T_{\mathrm{c}} / T_{\mathrm{o}}=0.7$ (Fig. 5) is higher than that for $T_{\mathrm{c}} / T_{\mathrm{o}}=0.5$ (Fig. 4) when $m_{\mathrm{c}} / m_{\mathrm{o}} \geqslant 5 \%$. Possible reasons for such a behavior include nonlinear effects via compressibility of air under the engine conditions. It may be noted that values for the ratio of coolant momentum to inlet momentum flow are also given in Figs. 4 and 5. While Fig. 5 presents results for the same four values of $m_{\mathrm{c}} / m_{0}$ as in Fig. 4, values for the $I_{\mathrm{c}} / I_{\mathrm{o}}$, ratio are higher for the results in Fig. 5 as compared to those in Fig. 4. This is due to the higher coolant temperature for the results in Fig. 5. Note that while $m_{\mathrm{c} i} m_{\mathrm{o}}$ is proportional to $B_{\mathrm{r}}$, the ratio $I_{\mathrm{c}} / I_{\mathrm{o}}$ is approximately proportional to $B_{\mathrm{p}}^{2} T_{\mathrm{c}} / T_{\mathrm{o}}$. Figure 6 shows the adiabatic effectiveness contours over the VKI rotor for $T_{c} / T_{\mathrm{o}}=0.7$ and for the same four values of $I_{\mathrm{c}} / I_{\mathrm{v}}$ as in Fig. 4. A close examination of Figs. 4 and 6 reveals only minor differences compared to those between Figs. 4 and 5. Thus, the momentum ratio, rather than the mass flow ratio, is the controlling factor.

The evidence for decreasing effectiveness values on the pressure side of shower-head holes $(0>$ $S>-0.3$ ) with increasing coolant flow when $T_{c} T_{4}=0.5$ is provided by the static temperature ratio ( $\left.T / T_{0}\right)$ contours on the left side of Figs. 7-10. The ratio of coolant to inlet mass flow for these figures is, respectively, $0.0211,0.0356,0.0505$ and 0.0654 , while the ratio of coolant to inlet momentum flow is, respectively, $0.0066,0.0188,0.0376$ and 0.0629 . The centerbottom portion of these figures shows the VKI rotor with six rows of holes located by black lines, and four more locations (where temperature ratio contours are displayed) shown in green. A blow-up of the front part of the blade is also shown in the center-top portion. The temperature ratio contours in the $y-z$ plane are shown at four streamwise locations represented by different values of the index $i$. While $i=167$ represents the shower-head hole spanwise centerline on the pressure side $(s / d=-2.85), i=166$, 160,154 and 148 represent locations about $0.25 d, 2.3 d$, $7.6 d$ and $15.9 d$ downstream, respectively, of the $i=167$ location. The last location $(i=148)$ is about $12.7 d$ upstream of the centerline of the pressure-side hole at $s / d=-31.5$. It is clear from the contours in Fig. 7 that the coolant jet is attached to the blade surface even at $i=148$, while in Fig. 8 at $i=154$ hot gas from the freestream has migrated to the blade surface due to lift off of the coolant jet from the blade surface. The coolant jet is thus no longer effective in cooling the surface. This is due to the secondary flow within the coolant jet, and the resulting entrainment of the hot gas from the outer region towards the airfoil surface between the adjacent jets. The lift-off is a jetcrossflow interaction based upon pressure fields and momentum balances [21]. The penetration of the coolant jet from the shower-head holes depends mainly on the injection angle, on the momentum ratio $\left(\rho_{c} V_{c}^{2}\right)$ 


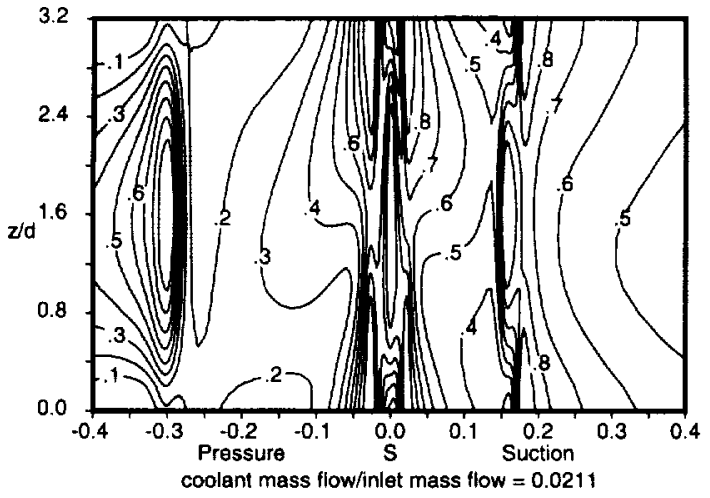

coolant momentum flow/inlet momentum flow $=0.0066$

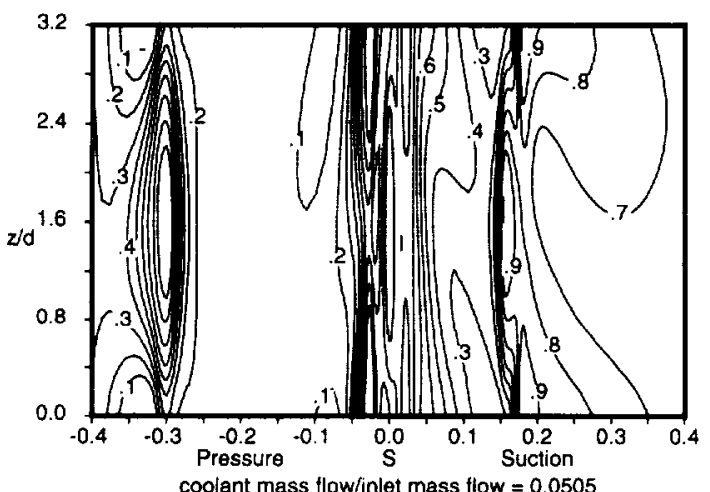

coolant momentum flow/inlet momentum flow $=0.0376$

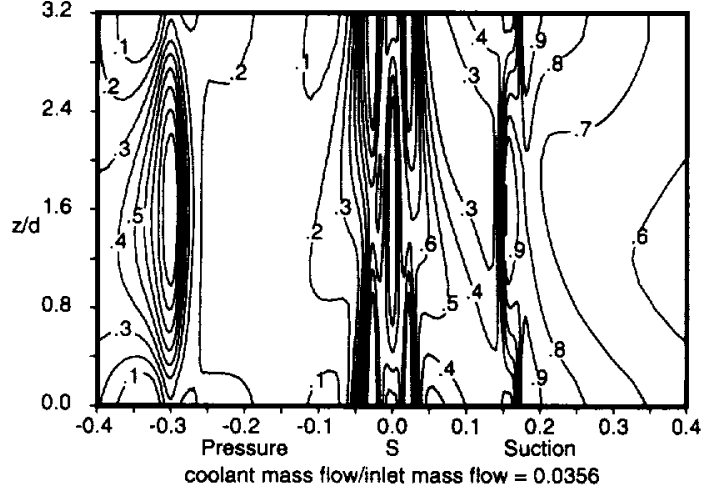

coolant momentum flow/inlet momentum flow $=0.0188$

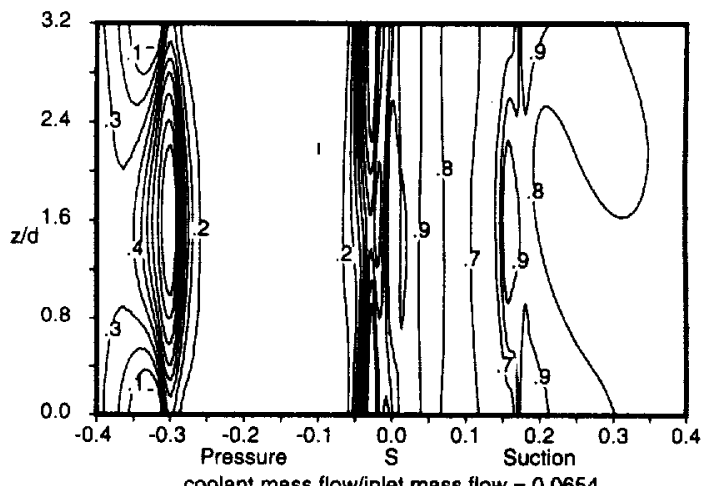

Coolant mass flow/inlet mass flow $=0.0654$ coolant momentum flow/iniet momentum flow $=0.0629$

Fig. 4. Adiabatic effectiveness contours on the VKI rotor surface when $T_{c} T_{0}=0.5$.
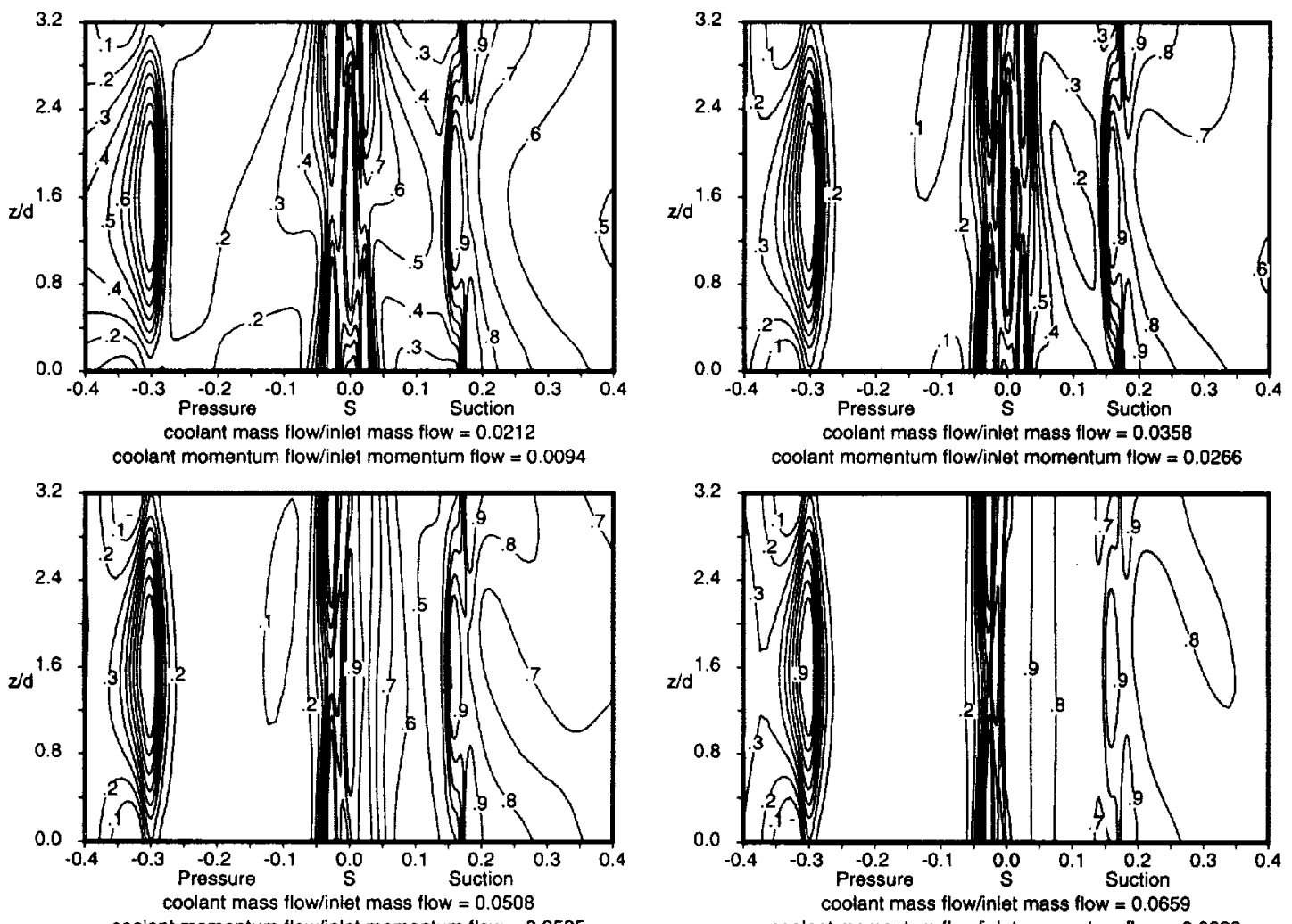

Fig. 5. Adiabatic effectiveness contours on the VKI rotor surface when $T_{0} T_{0}=0.7$ 

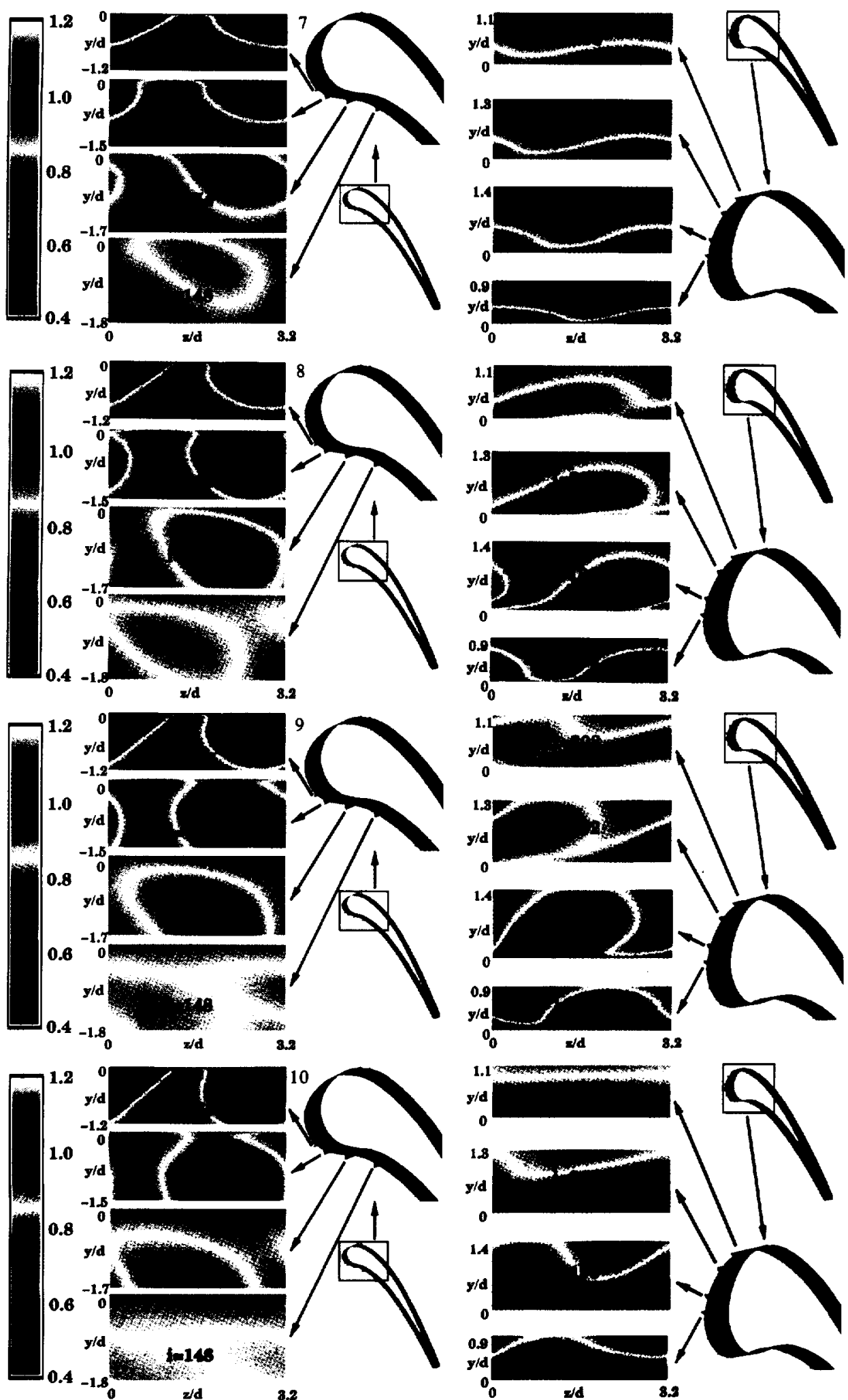

Fig. 7. Static temperature ratio contours at some streamwise locations when $T_{\mathrm{c}} / T_{\mathrm{o}}=0.5, m_{\mathrm{c}} / m_{\mathrm{o}}=2.11 \%$ and $I_{\mathrm{c}} / I_{\mathrm{o}}=0.66 \%$.

Fig. 8. Static temperature ratio contours at some streamwise locations when $T_{\mathrm{c}} / T_{\mathrm{o}}=0.5, m_{\mathrm{c}} / m_{\mathrm{o}}=3.56 \%$ and $I_{\mathrm{c}} / I_{\mathrm{o}}=1.88 \%$

Fig. 9. Static temperature ratio contours at some streamwise locations when $T_{\mathrm{c}} / T_{\mathrm{o}}=0.5, m_{\mathrm{c}} / m_{\mathrm{o}}=5.05 \%$ and $I_{c} I_{\mathrm{o}}=3.76 \%$

Fig. 10. Static temperature ratio contours at some streamwise locations when $T_{\mathrm{c}} / T_{\mathrm{o}}=0.5, m_{\mathrm{c}} / m_{\mathrm{o}}=6.54 \%$ and $I_{\mathrm{c}} / I_{\mathrm{o}}=6.29 \%$. 

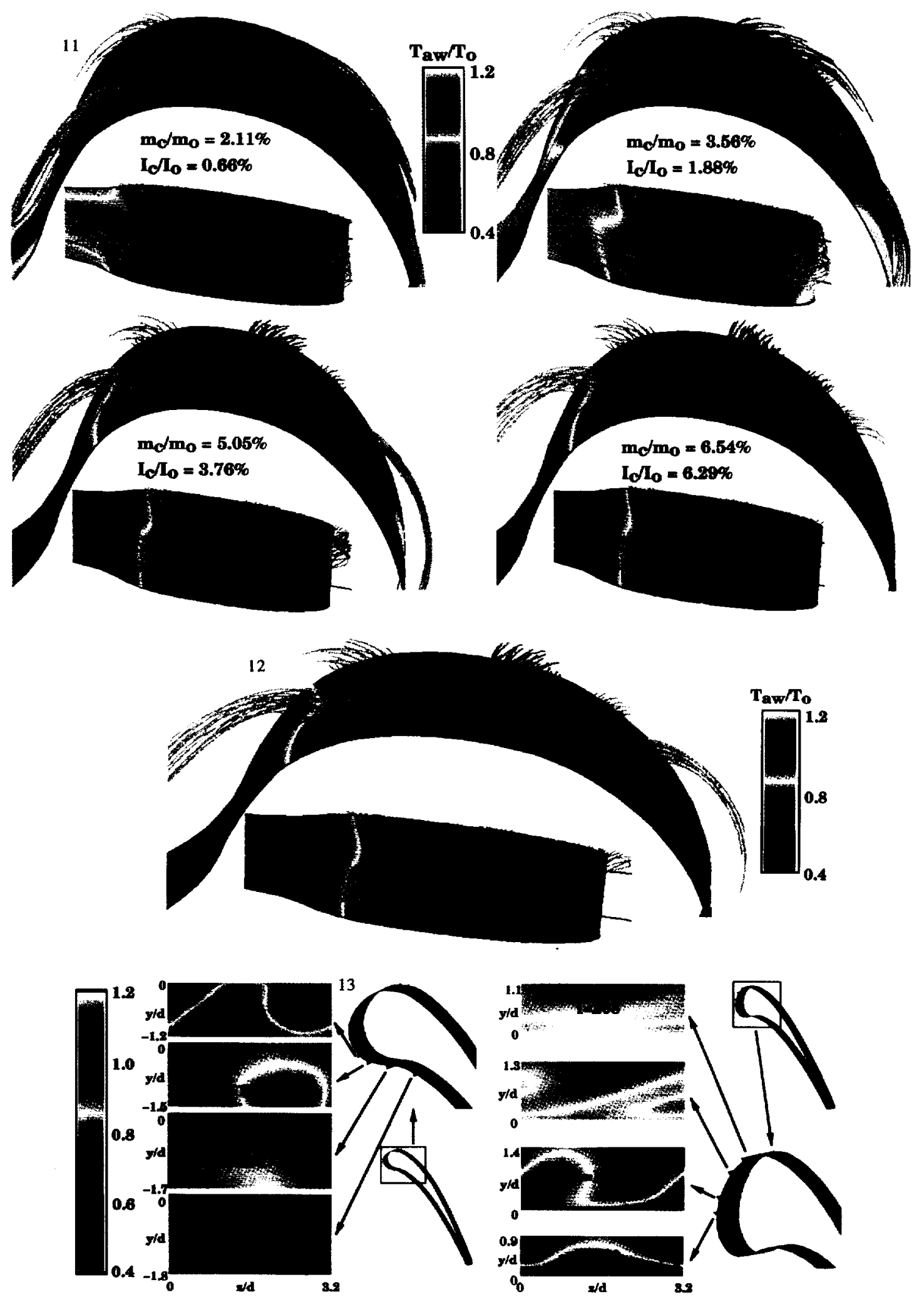

Fig. 11. Coolant particle traces from shower-head holes on the VKI rotor when $T_{\mathrm{c}} / T_{\mathrm{o}}=0.5$.

Fig. 12. Coolant particle traces from shower-head holes on the VKI rotor when $T_{\mathrm{c}} / T_{\mathrm{o}}=0.7, m_{\mathrm{c}} / m_{\mathrm{o}}=5.08 \%$ and $I_{c} / I_{\mathrm{o}}=5.35 \%$

Fig. 13. Static temperature ratio contours at some streamwise locations when $T_{\mathrm{c}} / T_{\mathrm{o}}=0.7, m_{\mathrm{c}} / m_{\mathrm{o}}=5.08 \%$ and $I_{\mathrm{c} /} I_{\mathrm{o}}=5.35 \%$. 

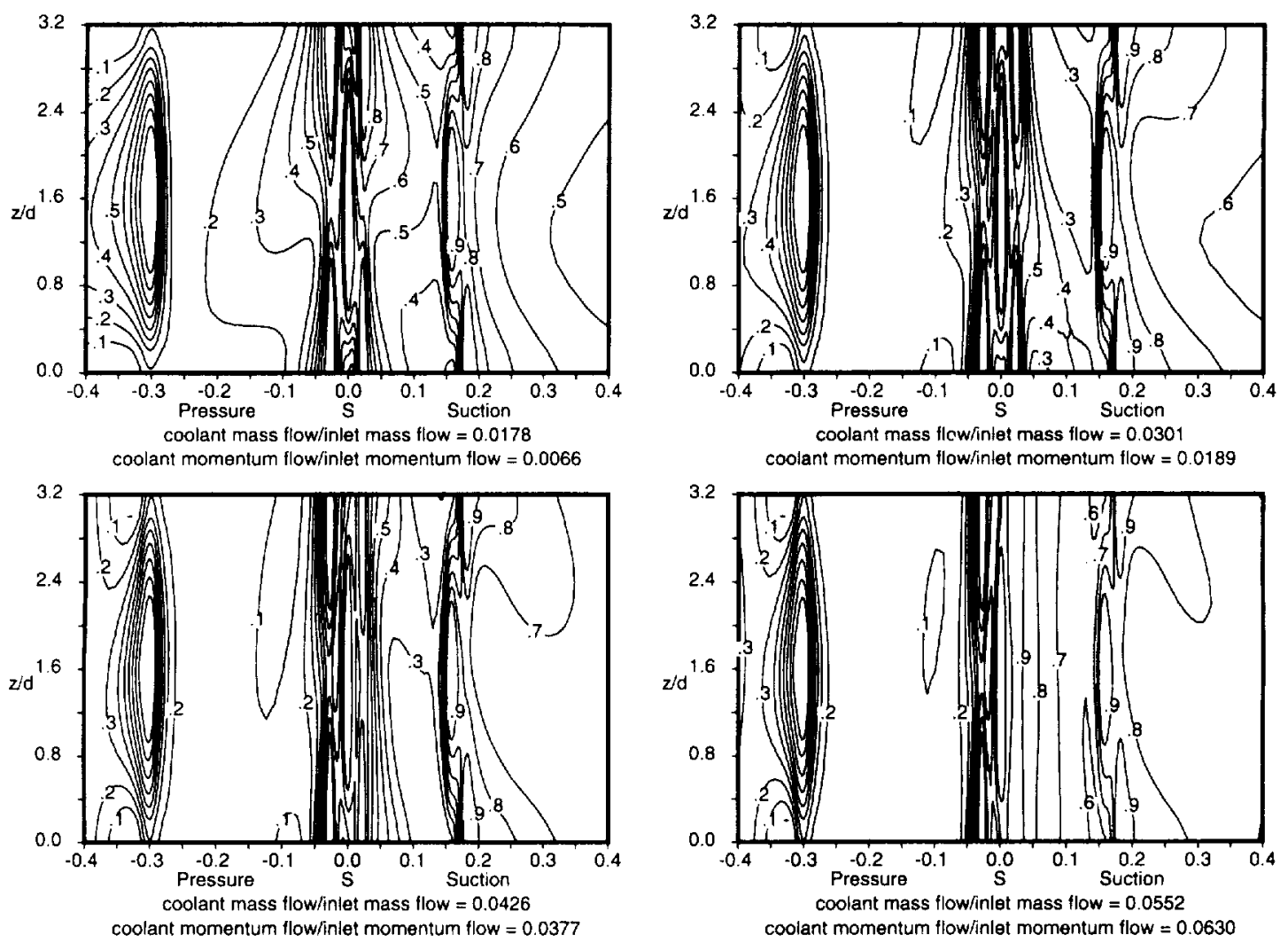

Fig. 6. Adiabatic effectiveness contours on the VKI rotor surface when $T_{4} T_{10}=0.7$.

$\left(\rho_{c} V_{c}^{2}\right)$, and on the pitch-to-diameter ratio. While the injection angle and pitch-to-diameter ratio were kept constant, the momentum ratio was varied in the present study. As the coolant mass flow increases further, the coolant jet lifts off sooner (cf. Figs. 9 and 10) resulting in lower values of $\eta$ over $0>S>-0.3$.

Let us now turn our attention to the suction side of shower-head holes $(0<S<0.15)$. The right-half of Figs. 7 to 10 shows the temperature ratio contours at four locations downstream of the hole centerline at $s / d=2.85$. The relative position of these four locations are again shown in green on the blow-up of the front part of the VKI rotor (see the right-lower corner of these figures). Here $i=190,196,202$ and 208 represent locations about $0.8 d, 3.5 d, 9.9 d$ and $15.65 d$ downstream, respectively, of the centerline $(i=187)$ of the shower-head hole at $s d=2.85$. The last location $(i=208)$ is only about $2.1 d$ upstream of the centerline of suction-side hole at $s d=20.6$. At low coolant mass flow $\left(m_{\mathrm{c}} m_{0}=2.11 \%\right)$, the coolant covers the blade surface well as shown by the temperature ratio contours in the right-half of Fig. 7 . However, when $m_{c} m_{0}=3.56$ or $5.05 \%$ (Figs. 8 and $9)$, the coolant does not cover the blade surface well; portions of the blade surface get exposed to the hot freestream. In Fig. 8. it is the ends of the computational domain that remain exposed to the hot freestream (see the contours at $i=196$ ), while in Fig. 9, it is the central portion of computational domain that is exposed to the hot freestream (contours at $i=202$ ). When the coolant mass flow increases further, $m_{v} / m_{i}=6.54 \%$ as in Fig. 10 , a thick blanket of coolant covers the entire blade span leading to high values of the effectiveness.

In order to understand this better. Fig. 11 shows the particle traces for the coolant emanating from the shower-head holes for the four values of the coolant mass flow corresponding to those for Figs. 7-10. For all the cases in this figure $T_{c} T_{0}=0.5$, and the adiabatic wall temperature ratio contours. $T_{\text {ax }} T_{3 .}$ are shown on the blade surface. Also, the shower-head region is zoomed in: the leading edge runs through the center of tan color traces emanating from the shower-head hole at the leading edge: the left-band side is the pressure side and the right-hand side is the suction side of the blade. Near the center of the figure. the spanwise direction is nearly vertical. Pink color traces are shown emanating from the shower-head holes located at $s / d= \pm 2.85$. Figure 11 shows that when $m_{\mathrm{s}} m_{0}=2.11 \%$, the coolant covers the blade span well and remains fairly attached to the blade surface due to the low coolant mass flow ratio (as well as low coolant momentum ratio). Recall that periodic boundary conditions apply at the ends of the computational span. In order to avoid confusion, traces resulting from this periodicity condition are not shown in Fig. 11. When $m_{c} m_{c}=3.56 \%$. the coolant traces lift-off the pressure surface, as described earlier. 
while the coolant traces from one staggered hole (on the suction side of the shower-head) lead to the hole in the adjacent row, leaving the portion between the holes uncovered. In such a situation, better cooling would have resulted if the shower-head holes were not staggered. Notice also that the ends of the (computational) span are hotter than the central portion on the suction side when $m_{\mathrm{c}} / m_{\mathrm{o}}=3.56 \%$.

When $m_{\mathrm{c}} / m_{\mathrm{o}}$ rises to $5.05 \%$, the coolant traces liftoff the pressure side earlier, leading to higher adiabatic wall temperature and thus lower $\eta$ on the pressure side. On the suction side, the coolant lift-off is clearly visible with the central part of the span hotter than the ends. Due to higher momentum of the coolant, the coolant jet does not get deflected by the mainstream as much as when $m_{\mathrm{v}} / m_{\mathrm{o}}<5 \%$. When the coolant mass flow increases further so that $m_{\mathrm{c}} / m_{\mathrm{o}}=6.54 \%$, the coolant momentum is enough to cause little deflection of the coolant jet on the suction side, with the result that the blade span is very well covered by the coolant on the suction side of the shower-head holes, leading to high values of $\eta$. On the pressure side of showerhead holes, the coolant lifts off earlier leading to lower values of $\eta$.

As already pointed out, the adiabatic effectiveness is generally lower for $T_{\mathrm{c}} / T_{\mathrm{o}}=0.7$ than that for $T_{\mathrm{c}} / T_{\mathrm{a}}=0.5$. However, over the suction side of showerhead holes $(0<S<0.15) \eta$ for $T_{\mathrm{c}} / T_{\mathrm{o}}=0.7$ (Fig. 5) is higher than that for $T_{\mathrm{c}} / T_{\mathrm{o}}=0.5$ (Fig. 4) when $m_{\mathrm{c}} / m_{\mathrm{o}} \geqslant 5 \%$. To understand this phenomenon, we look at the coolant particle traces from the showerhead holes in Fig. 12 for $T_{\mathrm{c}} / T_{0}=0.7$ and $m_{\mathrm{c}} / m_{\mathrm{o}}=5.08 \%$. Due to the higher coolant momentum for this case (about $140 \%$ of that for the case in Fig. 11, even though both have the same coolant mass flow), we find that the coolant jet gets less deflected by the mainstream on the suction side as compared to that in Fig. 11. It is thus able to cover the blade span well, leading to higher effectiveness on the suction side. On the pressure side, however, the higher momentum leads to an earlier lift-off, as is clear from a comparison of Figs. 9 and 13; compare, for example, the temperature ratio contours at $i=154$ in the two figures. A comparison of Figs. 9 and 13 reveals that the temperature level, in general, is lower in Fig. 9 due to the lower coolant temperature. On the suction side of shower-head holes, comparing the contours for $i=202$ in Figs. 9 and 13 reveals that the blade span is almost uniformly cool for the case in Fig. 13, while part of it is hot in Fig. 9. Increasing the coolant mass flow ratio beyond $5 \%$ with $T_{\mathrm{c}} / T_{\mathrm{o}}=0.7$ basically enhances these effects due to still higher ratio of the coolant to inlet momentum flow.

\section{CONCLUSIONS}

It is found that the adiabatic effectiveness is generally lower for a higher coolant temperature due to nonlinear effects via compressibility of air. However, over the suction side of shower-head holes, the effec- tiveness is higher for a higher coolant temperature than that for a lower coolant temperature when the coolant to mainstream mass flow ratio is $5 \%$ or more. For a fixed coolant temperature, the effectiveness passes through a minima on the suction side of shower-head holes as the coolant to mainstream mass flow ratio increases, while on the pressure side of shower-head holes, the effectiveness decreases with increase in coolant mass flow due to coolant jet liftoff. Thus, different effects are observed on the pressure and suction surfaces of the blade. Clearly, studies on a flat plate cannot reveal these differences. Moreover, in all cases, the adiabatic effectiveness is highly threedimensional. Thus span-averaged effectiveness values should be considered with caution.

Acknowledgements - Most of this work was done when the first author held a National Research Council-NASA Research Associateship at the NASA Lewis Research Center. This was presented as ASME Paper 95-WA/HT-1 : we acknowledge permission from ASME to publish it.

\section{REFERENCES}

1. R. J. Goldstein, Film cooling. In Advances in Heat Transfer (Edited by T. F. Irvine, Jr and J. P. Hartnett), Vol. 7, pp. 321-379. Academic Press, New York (1971).

2. V. K. Garg and R. E. Gaugler, Heat transfer in filmcooled turbine blades, ASME paper 93-GT-81 (1993).

3. V. K. Garg and R. E. Gaugler, Prediction of film cooling on gas turbine airfoils, ASME paper 94-GT-16 (1994).

4. V. K. Garg and R. E. Gaugler, Leading edge film cooling effects on turbine blade heat transfer, ASME paper 95GT-275 (1995).

5. B. Weigand and S. P. Harasgama, Computations of a film cooled turbine rotor blade with non-uniform inlet temperature distribution using a three-dimensional viscous procedure. ASME paper 94-GT-I5 (1994).

6. J. S. Liu, R. Utz and R. Bozzola, Aerodynamic design and analysis of a gas producer turbine stator with film cooling injection. AIAA paper 94-2928 (1994).

7. J. H. Leylek and R. D. Zerkle, Discrete-jet film cooling: a comparison of computational results with experiments, J. Turbomach. 116, 358 368 (1994).

8. A. Arnone, M.-S. Liou and L. A. Povinelli, Multigrid calculation of three-dimensional viscous cascade flows, AIAA paper 91-3238 (1991).

9. A. Jameson. W. Schmidt and E. Turkel, Numerical solutions of the Euler equations by finite volume methods using Runge $\mathrm{K}$ utta time-stepping schemes, AIAA paper 81-1259 (1981).

10. B. S. Baldwin and H. Lomax, Thin-layer approximation and algebraic model for separated turbulent flows, AIAA paper 78-257 (1978).

11. R. J. Boyle and P. Giel, Three-dimensional NavierStokes heat transfer predictions for turbine blade rows, AIAA paper $92-3068$ (1992).

12. A. A. Ameri and A. Arnone, Transition modeling effects on turbine rotor blade heat transfer predictions, ASME paper 94-GT-22 (1994).

13. A. A. Ameri and A. Arnone, Prediction of turbine blade passage heat transfer using a zero and a two-equation turbulence model. ASME paper 94-GT-122 (1994).

14. R. J. Boyle and A. A. Ameri. Grid orthogonality effects on predicted turbine midspan heat transfer and performance. ASME paper 94-GT-123 (1994).

15. E. J. Hall, D. A. Topp and R. A. Delaney, Aerodynamic heat transfer analysis of discrete site film-cooled turbine airfoils, AIAA paper $94-3070$ (1994). 
16. R. A. Graziani, M. F. Blair, J. R. Taylor and R. E Mayle, An experimental study of endwall and airfoil surface heat transfer in a large scale turbine blade cascade. J. Engng Power 102, 257267 (1980).

17. A. A. Amer. B. A. Jubran and M. A. Hamdan. Comparison of different two-equation turbulence models for prediction of film cooling from two rows of holes. Numer. Heat Transfer A 21, 143162 (1992).

18. S.-W. Kim and T. J. Benson, Calculation of a circular jet in cross flow with a multiple-time-scale turbulence model, Int. J. Heat Mass Transfer 35, 2357. 2365 (1992).
19. C. Camci and T. Arts, An experimental convective heat transfer investigation around a film-cooled gas turbine blade. J. Turbomach. 112, 497503 (1990).

20. V. K. Garg and R. E. Gaugler. Effect of velocity and temperature distribution at the hole exit on film cooling of turbine blades, ASME paper 95-GT-2 (1995). (Also to appear in $J$. Turbomach.)

21. W. Haas, W. Rodi and B. Schönung. The influence of density difference between hot and coolant gas on film cooling by a row of holes : predictions and experiments. ASME paper 91-GT-255 (1991). 
